\title{
Amorphous Silicon Carbide Nanowires for Optical Sensor Device
}

\author{
A. Boukezzata*, S. Bouanik, A. Manseri, S. Kaci, H. Menari and B. Mahmoudi \\ Centre de Recherche en Technologie des Semi-conducteurs pour l'Energétique (CRTSE), \\ Couches Minces Surfaces et Interfaces (CMSI), Algiers, Algeria
}

\begin{abstract}
In this study, amorphous silicon carbide nanowires (NWASC) on Si substrates were fabricated by depositing hydrogenated amorphous $\mathrm{SiC}$ thin films on silicon nanowire by $\mathrm{RF}$ magnetron sputtering, with different thicknesses. The scanning electron microscopy showed the formation of nanostructured NWASC and strong photoluminescence intensity was noticed. Due to the large surface area and the high stability, the $\mathrm{SiC}$ nanowires were used as the Schottky diode optical sensor device $(\mathrm{Au} / \mathrm{NWASC} / \mathrm{Si} / \mathrm{Al})$. The results presented in this work show the impact of the thickness and the surface structuring on the optoelectronic properties of amorphous SiC thin films. Finally, a high photocurrent and high relative spectral response value of $\mathrm{Au} / \mathrm{NWASC} / \mathrm{Si} / \mathrm{Al}$ were observed for the thinner amorphous $\mathrm{SiC}$ layer.
\end{abstract}

DOI: 10.12693/APhysPolA.137.447

PACS/topics: SiC nanowire, Schottky diode, optical sensor, photocurrent, spectral response

\section{Introduction}

Silicon carbide $(\mathrm{SiC})$ is an important semiconductor which can be operated at high powers, high temperatures, and high frequencies. Micrometer-sized whiskers of $\mathrm{SiC}$ have been widely used to strengthen ceramic composites which had brought dramatic revolution in mechanical and optoelectronic industries [1]. Furthermore, nanostructures of $\mathrm{SiC}[2]$ are of great interest because of their broad range of potential applications as field electron emitter, light emitter, and other reinforcing uses [38]. Considering these advantages of $\mathrm{SiC}$, it is worthwhile to fabricate efficient and stable photoelectrodes with favorable structures of SiC. Actually, such investigations have already been in progress. Bulk and film of the $\mathrm{SiC}$ have been employed as photocatalyst for water splitting [9-12]. It is known that the nanostructuration would greatly enlarge the specific surface areas of the $\mathrm{SiC}$ photocatalyst, and thus increase the reactive sites for photocatalysis. As a result, the efficiency of water splitting would be improved [13]. Results by Zhou et al. indicates that the $\mathrm{SiC}$ nanowires own a high photodegradation rate for acetaldehyde [14]. In particular, hydrogen amorphous silicon carbide (a-SiC:H) films have attracted much interest for their potential applications in many kinds of optoelectronic devices $[15,16]$. By controlling the carbon content in a- $\mathrm{Si}_{0.72} \mathrm{C}_{0.28}: \mathrm{H}$ films, the optical band gap could be readily adjusted between 1.8 and $3.2 \mathrm{eV}$, which makes them suitable candidates for application in fullcolor light emitting diodes (LED). In our previous work, we have studied the microstructures and optical properties of NWASC films prepared by two steps. In the first one, the formation of silicon nanowire on silicone type $p$

*corresponding author; e-mail: boukezzataassia@crtse.dz is done by metal-assisted chemical etching [17]. In the second one, hydrogenated amorphous $\mathrm{SiC}$ thin films are deposited on silicon nanowire by pulverization RF magnetron sputtering, with different thickness. The elaborated NWASC films are used to investigate devices for energy conversion.

\section{Experimental}

The formation of nanowire amorphous silicon carbide (NWASC) are prepared by two steps. First, elaborated silicon nanowires are done by metal-assisted chemical etching. Second, deposition of hydrogenated amorphous silicon carbide thin films on silicon nanowire, is done by $\mathrm{RF}$ magnetron sputtering of $p$-type $6 \mathrm{H}$-SiC polycrystalline, with different thickness. Moreover, we have studied the morphology and optical properties of NASC with of $\mathrm{SiC}$ thin films with differences thickness, using scanning electron microscopy (SEM), UV spectroscopy, and photoluminescence (PL). After formation of the ohmic contact as aluminum, the samples were placed into a deposition chamber in order to evaporate a thin layer of gold ( $\mathrm{Au}$, with $99.9 \%$ purity) on the NWASC to form the Schottky contact $(\mathrm{Au} / \mathrm{NWASC} / p-\mathrm{Si} / \mathrm{Al})$ to investigate devices for energy conversion.

\section{Results and discussion}

\subsection{Macrostructure of NWASC}

The morphologies and structures of the $\mathrm{Si}$ and $\mathrm{SiC}$ nanowire arrays were further characterized by SEM, and the results are shown in Figs. 1 and 2. It can be observed from Fig. 1 that the diameter and length of the Si nanowires are about $80 \mathrm{~nm}$ and $3 \mu \mathrm{m}$, respectively. Figure 2d demonstrates that the length of the NWASC are similar to those of the Si nanowires and the diameter increases with thickness of $\mathrm{SiC}$ layer, shown in Fig. 2a-d. 


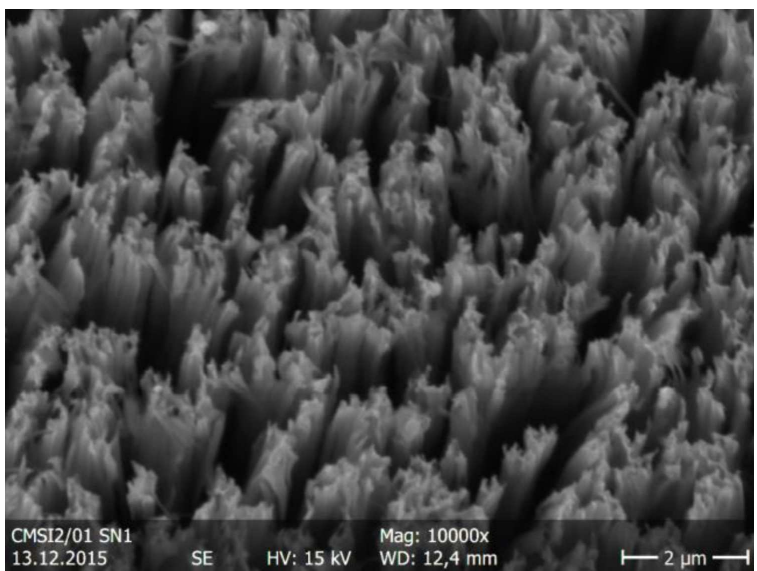

Fig. 1. SEM micrographs of silicon nanowire.

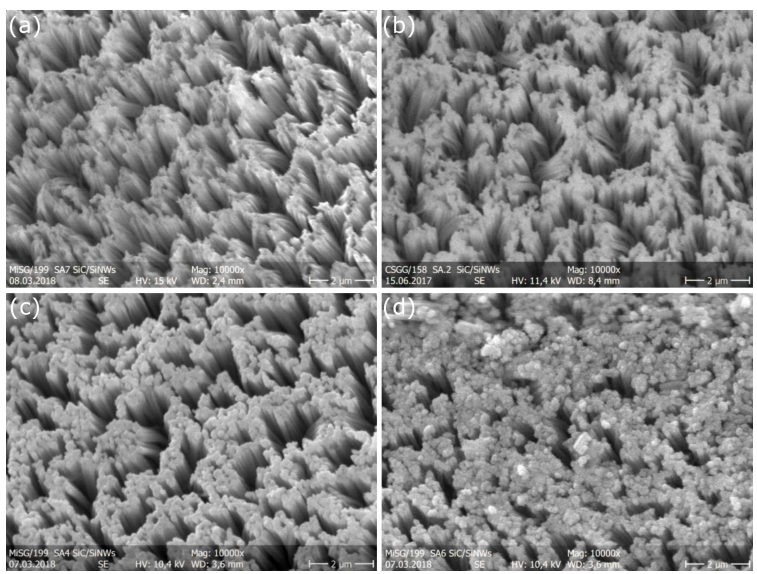

Fig. 2. SEM image of NWASC film grown on $p$-Si nanowire wafer with different thickness: (a) $E_{\mathrm{SiC}}=$ $2 \mathrm{~nm},(\mathrm{~b}) E_{\mathrm{SiC}}=10 \mathrm{~nm},(\mathrm{c}) E_{\mathrm{SiC}}=40 \mathrm{~nm}$, (d) $E_{\mathrm{SiC}}=60 \mathrm{~nm}$.

\subsection{Photoluminescence measurements}

The luminescence measurements were carried out at room temperature with a Perkin-Elmer LS-50B spectrometer and a xenon lamp (150 W) with an excitation wavelength of $325 \mathrm{~nm}$ was used. Figure 3 shows the PL spectra of NWASC which exhibits a high PL intensity in blue compared to the unetched a-SiC sample $[18,19]$. Wang et al. found that the PL intensities are enhanced by UV irradiation $325 \mathrm{~nm}$ at room temperature and the luminescence center with peak energy $2.20 \mathrm{eV}$ is induced by the UV light for the porous-like SiC samples. They suggested that UV irradiation may induce metastable states as luminescence centers in the sample [20,21].

\subsection{Realization and characterization of AuNASC device}

\subsubsection{AuNASC device}

In order to study the electrical and optical performance of the formed NWASC layers a diode configuration has been realized. Figure 4 shows the top view of $\mathrm{Au} / \mathrm{NWASC} / \mathrm{SNW} / p$-Si/AlSchottky diode structure.

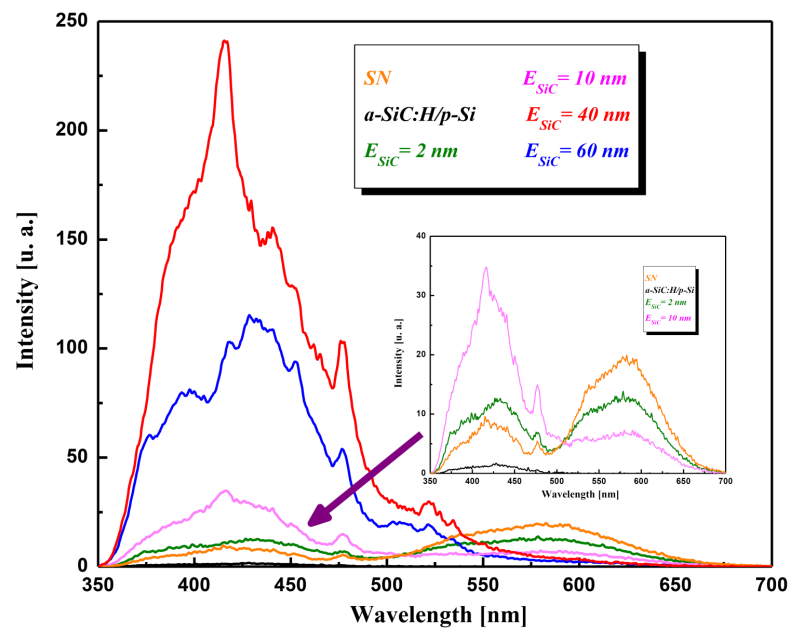

Fig. 3. Photoluminescence spectra of $\mathrm{Si}$ nanowire, a-SiC:H $/ p$-Si and NWASC films with different thickness.

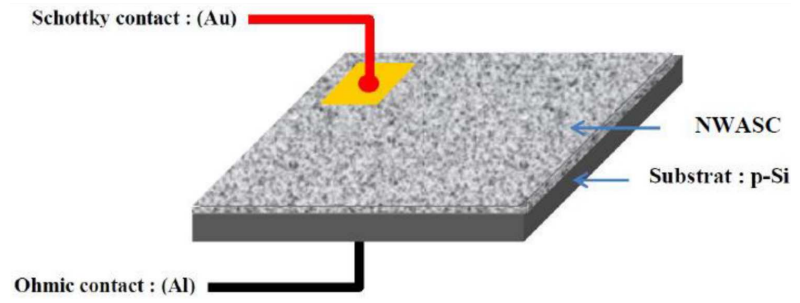

Fig. 4. Top view of $\mathrm{Au} / \mathrm{NWASC} / \mathrm{SNW} / p$-Si/Al Schottky diode structure.

\subsubsection{Device responses}

- Characterization $I-V$ of $\mathrm{Au} / \mathrm{NWASC} / \mathrm{SNW} / p-\mathrm{Si} / \mathrm{Al}$ device

Figure 5 shows the current-voltage characteristic of the $\mathrm{Au} / \mathrm{NWASC} / \mathrm{SNW} / p$-Si/Al heterojunction measured in the dark and under illumination at room temperature. Typically good rectifying and photoelectric behaviour were observed for the device. The dark leakage current is small, whereas its photocurrent generated under illumination is higher. It is observed that the heterojunction exhibits a rectifying behaviour in the presence of light, too. Under reverse bias conditions photocurrent caused by the NWASC/SNW $/ p$-Si heterojunction, which was irradiated under illumination by white light lamp, was evidently much larger than the dark current.

- Schottky photodiode application of $\mathrm{Au} / \mathrm{NWASC} /$ $\mathrm{SNW} / p$-Si/Al Schottky photodiodes

The photodiode spectral responsivity was in direct relation with the depletion width $(W)$ and thus with silicon carbide layer resistivity. The spectral response (SR) is given by the formula:

$$
\mathrm{SR}[\mathrm{A} / \mathrm{W}]=\frac{I_{\mathrm{ph}}}{Q} \frac{P_{\mathrm{inc}}}{h \nu}
$$

where $P_{\text {inc }}$ is the incident power and $h \nu$ is the photon energy. 

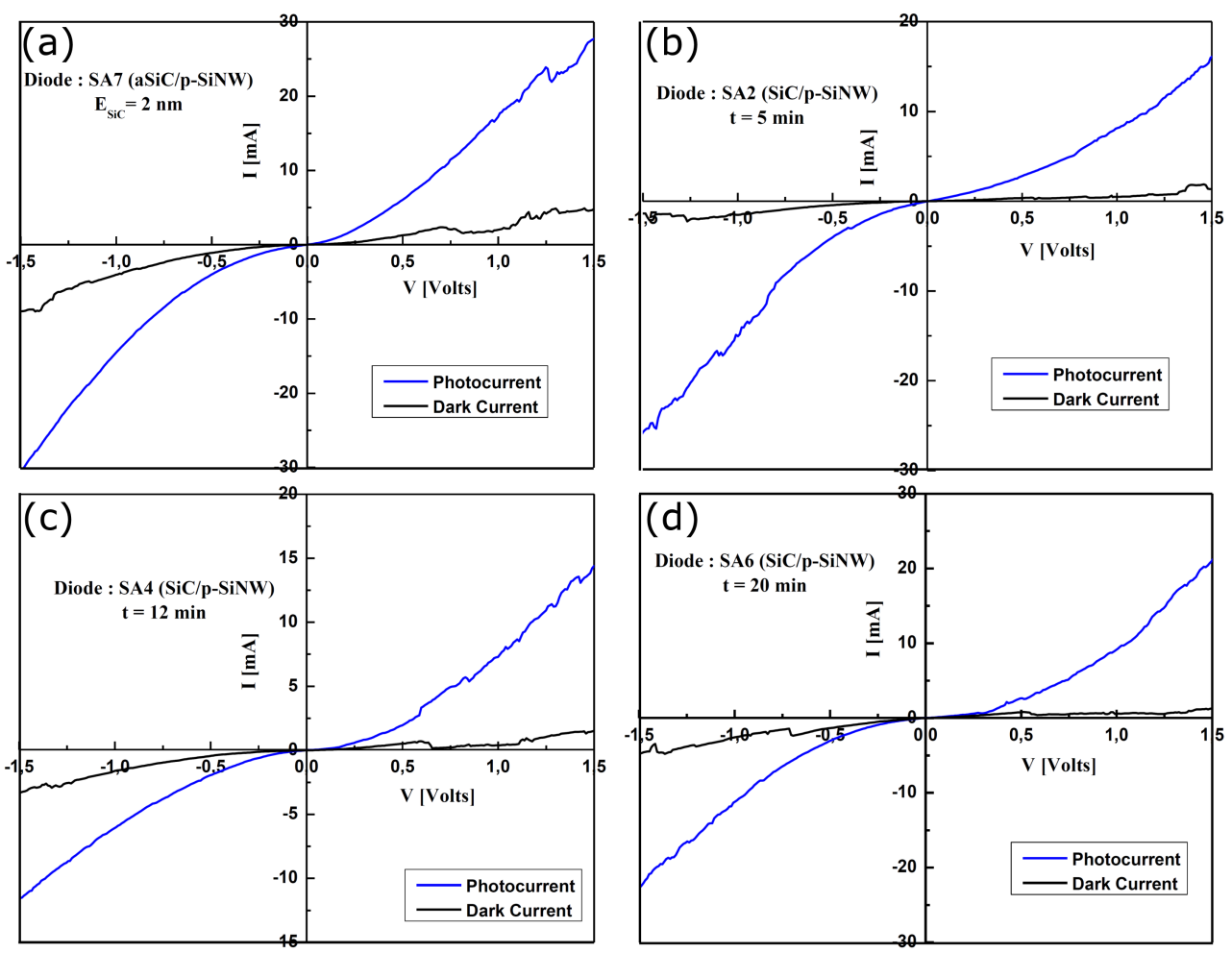

Fig. 5. $I-V$ characteristics curves $\mathrm{Au} / \mathrm{NWASC} / \mathrm{SNW} / p$-Si/Al heterojunction in dark and in light (light $38 \mathrm{~W}$ white lamp): (a) $E_{\mathrm{SiC}}=2 \mathrm{~nm}$, (b) $E_{\mathrm{SiC}}=10 \mathrm{~nm}$, (c) $E_{\mathrm{SiC}}=40 \mathrm{~nm}$, (d) $E_{\mathrm{SiC}}=60 \mathrm{~nm}$.

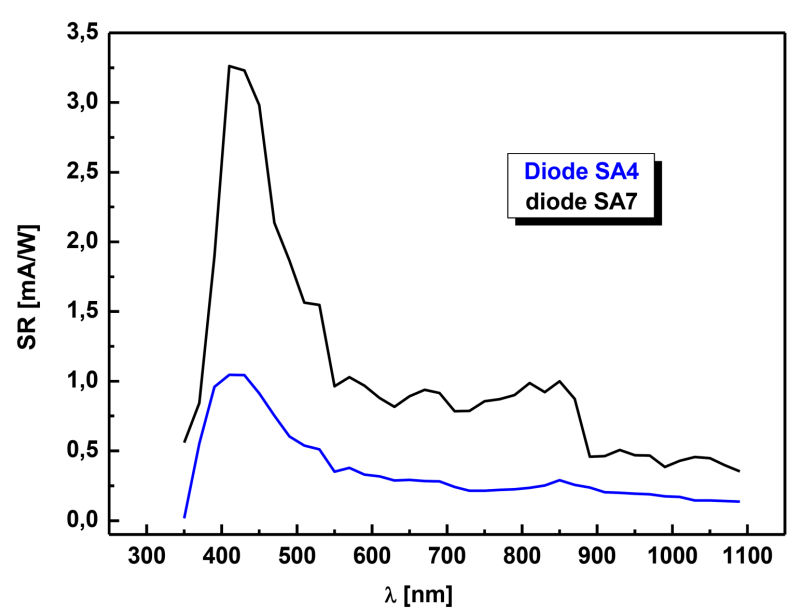

Fig. 6. Spectral response versus wavelength of $\mathrm{Au} / \mathrm{NWASC} / \mathrm{SNW} / p$-Si/Al heterojunction Schottky diode.

The results presented in this work show the impact of the surface structure on the SR of the $\mathrm{Au} / \mathrm{NWASC} / \mathrm{SNW} / p$-Si/Al Schottky photodiodes. A relatively high spectral response value of $3.25 \mathrm{~mA} / \mathrm{W}$ for $\mathrm{SiC}$ with thickness of $2 \mathrm{~nm}$ and $1 \mathrm{~mA} / \mathrm{W}$ for thickness of $40 \mathrm{~nm}$, in the blue region [22], reaching a maximum at a wavelength of $420 \mathrm{~nm}$ (Fig. 6), was obtained for device based on nanowires a-SiC, namely $\mathrm{Au} / \mathrm{NWASC} / \mathrm{SNW} /$ $p$-Si/Al Schottky photodiodes least thick.

\section{Conclusion}

In this work, we have discussed the formation of NWASC. This obtained structure encouraged us to elaborate devices based on this substrate such as $\mathrm{Au} / \mathrm{NWASC} / \mathrm{SNW} / p$-Si/Al Schottky diode. The obtained results indicated clearly the impact of the nanowire structure on the optical properties of the fabricated $\mathrm{Au} / \mathrm{NWASC} / \mathrm{SNW} / p$-Si/Al Schottky diode, where an increase of the photocurrent was noticed. Finally, the Schottky diodes realized with a nanowire thin $\mathrm{SiC}$ films $(\mathrm{Au} / \mathrm{NWASC} / \mathrm{SNW} / p$-Si/Al) showed a good rectifying behaviour which could allow the fabrication of the Schottky diodes for energy conversion.

\section{Acknowledgments}

This work was supported by Funds National Research (DG-RSDT/MESRS, Algeria).

\section{References}

[1] T. Ishikawa, Y. Kohtoku, K. Kumagawa, T. Yamamura, T. Nagasawa, Nature 391, 773 (1998).

[2] H. Dai, E.W. Wong, Y.Z. Lu, S. Fan, C.M. Lieber, Nature 375, 769 (1995).

[3] K.W. Wong, T. Zhou, C.K. Au, H.L. Lai, C.S. Lee, S.T. Lee, Appl. Phys. Lett. 75, 2918 (1999). 
[4] J.W. Liu, D.Y. Zhong, F.Q. Xie, M. Sun, E.G. Wang, W.X. Liu, Chem. Phys. Lett. 348, 357 (2001).

[5] Y.H. Gao, Y. Bando, K. Kurashima, T. Sato, J. Electron Microsc. 49, 641 (2000).

[6] A. Kassiba, M. Tabellout, S. Charpentier, N. Herlin, J.R. Emery, Solid State Commun. 115, 389 (2000).

[7] S. Kaci, R. Rahmoune, F. Kezzoula, et al., Opt. Mater. 80, 225 (2018).

[8] Y.H. Gao, Z. Zhang, L.S. Liao, X.M. Bao, J. Mater. Res. 12, 1640 (1997).

[9] C. Schnabel, M. Worner, B. Gonzalez, I. Del Olmo, M. Braun, Electrochim. Acta 47, 719 (2001).

[10] K.Q. Peng, Z.P. Huang, J. Zhu, Adv. Mater. 16, 73 (2004).

[11] J. Akikusa, S.U.M. Khan, Int. J. Hydrogen Energy 27, 863 (2002).

[12] D.H. Van Dorp, N. Hijnen, M.D. Vece, J.J. Kelly, Angew. Chem. Int. Ed. 48, 6085 (2009).

[13] H. Liu, G. She, L. Mu, W. Shi, Mater. Res. Bull. 47, 917 (2012).

[14] W.M. Zhou, L.J. Yan, Y. Wang, Y.F. Zhang, Appl. Phys. Lett. 89, 013105 (2006).
[15] A. Boukezzata, A. Keffous, S. Kaci, B. Mahmoudi, L. Guerbous, H. Menari, Y. Belkacem, J. Nanoelectron. Optoelectron. 14, 987 (2019).

[16] Y. Tawada, M. Tsuge, H. Kondo, Y. Okamoto, J. Hamakawa, J. Appl. Phys. 53, 5273 (1982).

[17] N. Brahiti, T. Hadjersi, S. Amirouche, H. Menari, O. ElKechai, Int. J. Hydrogen Energy 43, 11411 (2018).

[18] A.M. Ouadfel, A. Keffous, A. Kheloufi, et al., Opt. Mater. 65, 117 (2017)

[19] Z. Enlei, W. Guosheng, L. Xiaozhu, W. Zhumin, Bull. Mater. Sci. 37, 1249 (2014).

[20] J.N. Wang, Z.M. Chen, P.W. Woo, W.K. Ge, Y.Q. Wang, M.B. Yu, Appl. Phys. Lett. 74, 923 (1999).

[21] S. Kim, J.E. Spanier, I.P. Herman, Jpn. J. Appl. Phys. 39, 5875 (2000).

[22] A. Boukezzata, A. Keffous, N. Gabouze, et al., J. Nanoelectron. Optoelectron. 14, 321 (2019). 